\title{
Quantification of urine 17-ketosteroid sulfates and their age correlations
}

\author{
Qi Jia $^{\text {a,* }}$, Mei-Feng Hong ${ }^{\text {a }}$, Zhao-Xing Pan ${ }^{\mathrm{b}}$, Cheryl Ritter ${ }^{\mathrm{a}}$, Susan Vance ${ }^{\mathrm{a}}$, \\ Miriam Cortes-Guzman ${ }^{\mathrm{a}}$ and Stephen Cherniske ${ }^{\mathrm{c}}$ \\ ${ }^{a}$ Unigen Pharmaceuticals, Inc., 100 Technology Drive, Broomfield, CO 80021, USA \\ ${ }^{\mathrm{b}}$ National Center for Children, Families and Communities, Denver, CO 80218, USA \\ c Oasis Wellness Network, 100 Technology Drive, Broomfield, CO 80021, USA
}

\begin{abstract}
Dehydroepiandrosterone (DHEA) is a steroid secreted primarily by the adrenal gland and plays an important role as the primary precursor of many important sex steroids. The negative correlation between age and the secretion of DHEA (I) and in its sulfate form (II, DHEA-S) has been documented in human studies. Serum DHEA (I) and/or DHEA-S (II) levels have been associated with central nervous system function, immunity, cardiovascular functions, insulin sensitivity, and body composition. A high-performance liquid chromatography/ion trap mass spectroscopic method with sonic spray ionization (SSI) for the quantification of individual and total urinary 17-ketosteroid sulfates was developed. This quantification method had broad linearity range, low detection limit and high throughput. The amount of 17-KS-S, normalized by creatinine, in urine secreted over 24 hours versus that in early morning urines was found inversely correlated to age for both genders.
\end{abstract}

\section{Introduction}

Dehydroepiandrosterone (I, DHEA), also referred to as, dehydro-3-isoandrosterone or 3- $\beta$-hydroxyandrost-5-ene-17-one, is a steroid secreted primarily by the adrenal gland and plays an important role as the primary precursor of many important sex steroids [1]. The negative correlation between age and the secretion of DHEA (I) and its sulfate form (II, DHEA-S) has been documented in human studies [2,3]. Serum DHEA (I) and/or DHEA-S (II) levels have been reported constructive associations with central nervous system function, immunity, cardiovascular functions, insulin sensitivity, and body composition. Acute physiological trauma such as burns and serious illness are associated with decreases in DHEA and DHEA-S concentrations [4]. In recent years, "DHEA deficiency syndrome" has been introduced as a new term for old age and there has been an increasing interest in the potential anti-aging benefits from DHEA/DHEA-S replacement therapy [5]. The measurement of steroids in human serum and urine specimens has been utilized as a clinical indicator of adrenal function [6], androgen abuse in sports [7], and as a prediction of general health [8]. Recently, researchers at Hokkaido University in Japan discovered that total urinary 17-ketosteroid sulfate conjugates (17-KS-S) had a significant negative correlation with the health status of individuals [9]. The amount of 17-KS-S secreted over $24 \mathrm{~h}$ and adjusted by creatinine was inversely correlated to recovery from infection, illness, injury and psychosocial stress [10].

Urinary 17-ketosteroids consist primarily of 17-KS sulfates and 17-KS glucuronides (Fig. 1). Quantification of individual ketosteroid glucuronides and sulfates in biological fluids has been a great challenge due to the similarity of their structures and low concentrations. Radioimmunoassay has been widely utilized for quantification of DHEA/DHEA-S [11]. However, most of the ELISA kits have only been

\footnotetext{
*Corresponding author. Tel.: +1 303438 8666; Fax: +1 303438 9483; E-mail: qjia@upi1.com.
} 
<smiles>C[C@]12CCC3C(CC=C4C[C@H](O)CC[C@@]43C)[C@]1(C)CCC2=O</smiles>

I $\quad \mathrm{R}=\mathrm{H}$

II $\quad \mathrm{R}=\mathrm{SO}_{3} \mathrm{Na}$<smiles>C[C@]12CCC3C(CC[C@@H]4C[C@H](OS(C)(=O)=O)CC[C@]34C)C1CCC2=O</smiles>

III<smiles>C[C@@]12CCC3C(CC[C@@]4(C)C(=O)CCC34)[C@]1(C)C[C@H](OS(C)(=O)=O)CC2</smiles>

IV

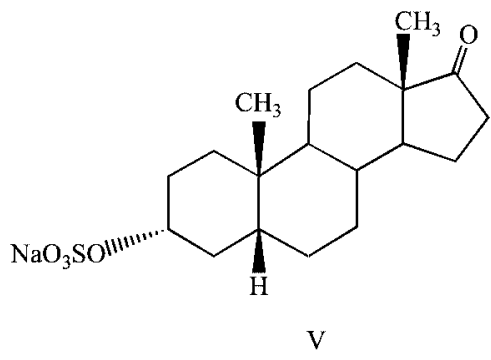

Fig. 1. Structure of dehydroepiandrosterone (I, DHEA), dehydroepiandrosterone-3- $\beta$-sulfate (II, DHEA-S), epiandrosterone-3- $\beta$-sulfate (III), androsterone-3- $\alpha$-sulfate (IV), etiocholanol-17-one-3- $\alpha$-sulfate (V).

designed for DHEA and/or DHEA-S and not for other 17-KS conjugates. Quantification by classical enzymatic and chemical hydrolysis followed by Zimmermann color reaction has limited diagnostic value due to non-specificity [12]. Extensive column chromatographic separation of ketosteroid sulfates from glucuronides [13], or chemical labeling followed by fluorescence HPLC quantification [14] are time consuming and unsuitable for large numbers of samples. Recently, mass spectroscopic detection together with GC has been described for quantification of 17-ketosteroids with [15] and without derivatization [16]. HPLC-MS also has been reported in the quantification of 17-ketosteroid sulfate in serum [17] and estrogen sulfates in urine [18]. Jia et al. reported using LC/MS to quantify Ketosteroid sulfates and glucuronides under high concentration of ammonium acetate buffer using super sonic ionization method [19].

The aim of this study is to develop and validate a methodology that quantifies 17-ketosteroid sulfate conjugates in human urine. The manuscript also reports an age correlation with indicated steroid sulfates in urine samples collected in morning verses 24-hour urine samples. The test throughput also has been evaluated for the potential usage in research regarding to the relation between steroids and aging/disease, and in monitoring steroid abuse in sports and in dietary supplement consumption.

\section{Experimental}

\subsection{Materials and reagents}

Dehydroepiandrosterone-3- $\beta$-sulfate (II, DHEA-S), epiandrosterone-3- $\beta$-sulfate (III), androsterone-3$\alpha$-sulfate (IV), and etiocholanol-17-one-3- $\alpha$-sulfate (V) were purchased from Sigma Chemicals with 
$>99 \%$ purity and used as analytical standards. ACS grade ammonium acetate, sodium hydrogenphosphate and sodium dihydrogenphosphate were purchased from Sigma. Acetonitrile, HPLC grade, and methanol, ACS grade, were purchased from Fisher. $\mathrm{C}_{18}$ Sep-Pak cartridges (Vac RC $500 \mathrm{mg}$ ) were purchased from Waters. Creatinine quantification kit (555-A) was purchased from Sigma.

\subsection{Instrumentation}

A Hitachi M-8000 ion trap mass spectrometer (LC-3DQ-MS) with a sonic spray ionization source was utilized for quantification in a negative ionization mode. The LC-MS was calibrated by direct injection of $10 \mathrm{ng} / \mu \mathrm{l}$ of total 17-ketosteroids using a Harvard Apparatus, Inc. model 11 syringe pump at a flow rate of $100 \mu \mathrm{l} / \mathrm{min}$. Unit mass resolution was established and maintained at $\pm 0.3 \mathrm{~m} / z$. Nitrogen gas was generated from a liquid nitrogen tank with output pressure of $60 \mathrm{psi}$ and ion source inlet pressure at $3.6 \mathrm{kgf} / \mathrm{cm}^{2}$; and helium gas was utilized as a buffer gas with output pressure of $60 \mathrm{psi}$ and ion source inlet pressure at $3.0 \mathrm{kgf} / \mathrm{cm}^{2}$. The sonic spray ion source plate had a temperature of $275^{\circ} \mathrm{C}$ with $1.0 \mathrm{kV}$ voltage. Aperture temperatures were set up at $170^{\circ} \mathrm{C}$ and $120^{\circ} \mathrm{C}$, respectively. The draft voltage was $75 \mathrm{~V}$ and the focus voltage was $35 \mathrm{~V}$. The ion accumulation time was $300 \mathrm{~ms}$ with a scan range of 300 to $500 \mathrm{~m} / z$. Negative-ion mass spectra of steroid sulfates and glucuronides are dominated by the anion $[\mathrm{M}-\mathrm{H}]^{-}$. This ion was used for selected-ion monitoring (SIM). A mass scan range at $[\mathrm{M}-\mathrm{H}]^{-} \pm 1 \mathrm{~m} / z$ was used for quantification in centroid mode to secure the highest sensitivity and reproducibility. An electronic spray ionization (ESI) experiment was run at same conditions as SSI except assistant gas and desolvator temperatures were $180^{\circ} \mathrm{C}$ with $3.0 \mathrm{kV}$ voltage at the probe. Aperture temperatures were set up at $150^{\circ} \mathrm{C}$ and $120^{\circ} \mathrm{C}$, respectively.

\subsection{Chromatographic conditions}

The mobile phase solvents were delivered by a Hitachi L-7100 gradient pump through a Hitachi inline degasser at a flow rate of $0.35 \mathrm{ml} / \mathrm{min}$. The mobile phase was composed of an isocratic solution of $0.2 \mathrm{mM}$ ammonium acetate-acetonitrile $(80: 20, \mathrm{v} / \mathrm{v})$ at time $t=0$ to $t=6.0$; then the column was washed with $0.2 \mathrm{mM}$ ammonium acetate-acetonitrile $(20: 80, \mathrm{v} / \mathrm{v})$ at time $t=6.1$ to $t=8.0$. A 5.0-min post run time was used to re-equilibrate the column with $0.2 \mathrm{mM}$ ammonium acetate-acetonitrile $\left(80: 20\right.$, v/v). A $\mathrm{C}_{18}$ column $(10.0 \times 2.0 \mathrm{~mm}$, I.D. Synergi, Phenomenex $)$ packed with $3 \mu \mathrm{m}$ diameter particles and protected with a $\mathrm{C}_{18}$ guard column (ODS, $4.0 \times 2.0 \mathrm{~mm}$, I.D. cartridge, Phenomenex) was used in a Hitachi L7300 column oven $\left(50.0 \pm 0.2^{\circ} \mathrm{C}\right)$. A Hitachi L-7200 sequential autosampler was utilized to inject $20.0 \mu \mathrm{l}$ samples that was kept in HPLC vials at $5 \pm 0.2^{\circ} \mathrm{C}$. The effluent from the column was transferred directly onto a Hitachi M-8000 ion trap mass detector connected with a D-7000 interface module.

\subsection{Extraction procedure}

A urine sample of $5 \mathrm{ml}$ was mixed with $5 \mathrm{ml}$ of $67 \mathrm{mM}$ sodium phosphate buffer $(\mathrm{pH}=7.0)$ and loaded onto a Sep-Pak $\mathrm{C}_{18}$ cartridge $(500 \mathrm{mg}$ ) activated with $5 \mathrm{ml}$ methanol and conditioned by $5 \mathrm{ml}$ $67 \mathrm{mM}$ sodium phosphate buffer. The column was washed with $3 \mathrm{ml}$ of DI water followed by $3 \mathrm{ml}$ $30 \%$ methanol, then dried under vacuum for $5 \mathrm{~min}$. The 17-ketosteroids were eluted with $3 \mathrm{ml}$ methanol and collected in a test tube. The solvent in the eluent was removed by a RapidVap at a vortex speed of $40 \mathrm{rpm} / \mathrm{min}$ at $35 \pm 1{ }^{\circ} \mathrm{C}$. The residue was dissolved in $2.5 \mathrm{ml}$ of the mobile phase, filtered through a $0.45 \mu \mathrm{m}$ filter and a $20-\mu \mathrm{l}$ aliquot was injected for LC-MS analysis. 


\subsection{Standard curve, recovery and stability}

Approximately $14 \mathrm{mg}$ of DHEA-S (II), $14 \mathrm{mg}$ of epiandrosterone-3- $\beta$-sulfate (III), $25 \mathrm{mg}$ of androsterone-3- $\alpha$-sulfate (VI), and $25 \mathrm{mg}$ of etiocholanol-17-one-3- $\alpha$-sulfate (V) were mixed with $100 \mathrm{mg}$ boric acid, added to a $100 \mathrm{ml}$ volumetric flask, and dissolved in HPLC mobile phase to yield a $0.78 \mu \mathrm{g} / \mu \mathrm{l}$ stock solution of total 17-ketosteroids. The stock solution was diluted 1:500 with the mobile phase to generate an external standard at a concentration of $1.5 \mathrm{ng} / \mu \mathrm{l}$. Calibration standards at concentrations of $35,17.5,10.5,7,1.5,0.7,0.35$ and $0.15 \mathrm{ng} / \mu \mathrm{l}$ of total $17-\mathrm{KS}$ were obtained by serial dilution of the stock solution. The recovery yields of 17-ketosteroid sulfates were measured by comparing 17-KS peak area ratios from a urine specimen spiked with and without known amounts of standards at two concentrations $(1.5$ and $6.0 \mathrm{ng} / \mu \mathrm{l})$ of total 17-ketosteroid sulfates. The urine samples were processed in triplicate and analyzed as described earlier. The stability of the standards was measured after storage at $-10 \pm 1^{\circ} \mathrm{C}$ for 2 months. Each determination was performed in duplicate.

\subsection{System suitability and data analysis}

The sample analysis started with one blank injection for background subtraction. Then an external standard at a concentration of $1.5 \mathrm{ng} / \mu \mathrm{l}$ total 17 -ketosteroid sulfates was injected in quintuplet. The LCMS system was judged suitable for quantification analysis if the mean peak areas and retention times for each individual 17-ketosteroid had less than $10 \%$ coefficient of variation (CV). The sample 17-KS concentration was calculated from the ratio of the peak area of the compound of interest to that of the external standard multiplied by its concentration. The concentration of creatinine in urine was measured by a colorimetric method [20]. The urinary Anabolic/Catabolic Index $(\mathrm{ACI}=X / Y)$ was calculated as a ratio of total 17-ketosteroid sulfate concentration $(X, \mathrm{ng} / \mu \mathrm{l})$ to creatinine concentration $(Y, \mu \mathrm{g} / \mu \mathrm{l})$.

\subsection{Urine specimens}

Urine specimens were collected in a period of 24-h from 66 normal human volunteers including 49 females and 17 males aged 40 to 65 . Total volume of each 24-hour urine specimen was recorded. The urine specimens were quickly aliquoted, frozen, and immediately shipped on dry ice by overnight service. These specimens were thawed at room temperature and processed as described on the same day of receipt.

The urine samples collected at morning time were submitted by 1565 individuals with filed forms that included information about gender, age, urine collection time, and current intakes of medications and nutritional supplements, especially, any hormones, DHEA and creatine. The urine specimens were collected between 8:00 am to 10:00 am, but not the first urine in the morning, with a volume of 20-80 ml. Boric acid and thymol were used as preservatives, $200 \mathrm{mg}$, respectively, in each urine container. The urine specimens were shipped on the same day of the collections by overnight service. Those specimens were processed as described on the same day of receipt.

Pearson correlation coefficient is used to quantify the relation between age and total 17-KS-S. Twotailed $t$-test was used to test whether a correlation coefficient was significant from zero [21]. 


\section{Results and discussion}

\subsection{Mass spectroscopic results}

Figure 2(A) showed total ion chromatogram (TIC) of four 17-ketosteroid sulfate (17-KS-S) standards, which were analyzed within ten minutes using a $\mathrm{C}_{18}$ HPLC column. Compared to the previously published method [19] that was designed to quantify not only 17-ketosteroid sulfate but also 17-KS glucuronides conjugates under high concentration of ammonium acetate $(0.1 \mathrm{M})$ with longer separation time (20 minutes), the method presented in this manuscript is ten times more sensitive and sevenminutes shorter of running time for each sample. However, it could not separate androsterone sulfate (IV) from etiocholanolone sulfate (V). Figure 2(B) is a total ion chromatogram (TIC) of a representative urine specimen. The individual $17-\mathrm{KS}-\mathrm{S}$ was identified and quantified based on select ion chromatogram (SIC) and retention time. Figures 3-4 show the mass spectra and selective ion chromatograms (SIC) of $17-\mathrm{KS}-\mathrm{S}$ conjugates. It is true for every $17-\mathrm{KS}-\mathrm{S}$ conjugate that $[\mathrm{M}-1]^{-}$ion is the base peak in the full scan mode without significant fragmentation. Therefore, the intensity of the $[\mathrm{M}-1]^{-}$peak was utilized for quantification. Dehydroepiandrosterone-3- $\beta$-sulfate (DHEA-S) can be identified obviously from the high intensity $[\mathrm{M}-1]^{-}$ion at 366-368 $\mathrm{m} / z$ (Fig. 3(A) \& (B)). Epiandrosterone-3- $\beta$ sulfate (III), androsterone-3- $\alpha$-sulfate (IV) and etiocholanol-17-one-3- $\alpha$-sulfate (V) have same [M - 1] ${ }^{-}$

A

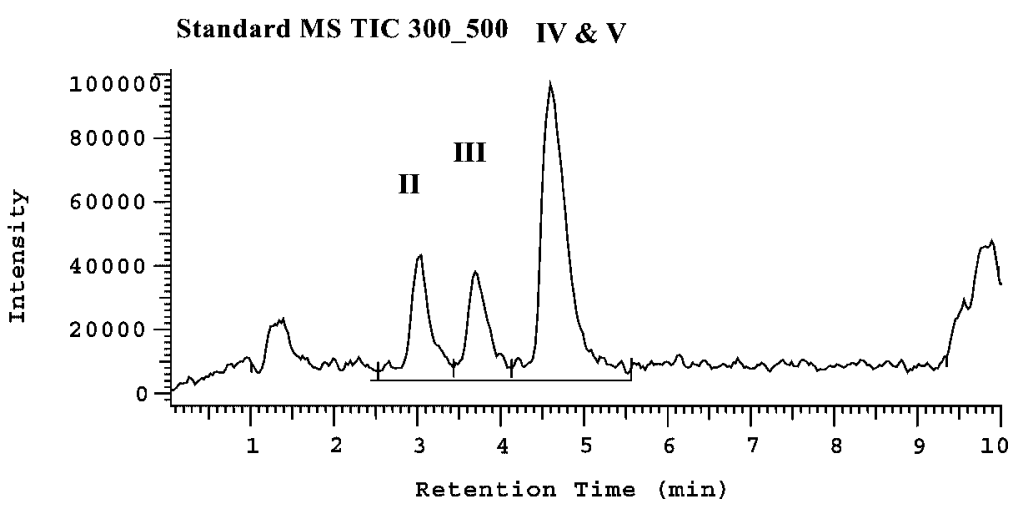

Standard MS TIC 300500

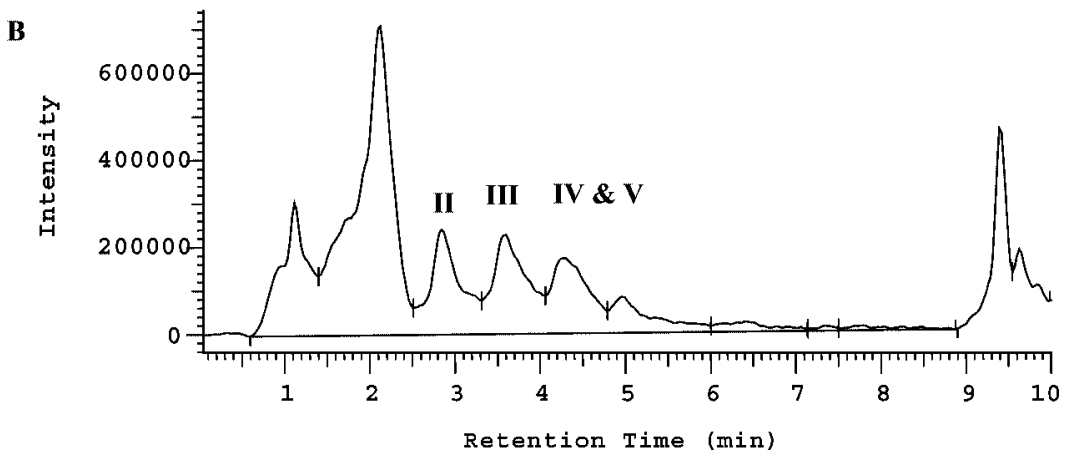

Fig. 2. (A) Total Ion Chromatogram (TIC) of four 17-KS-S standards; dehydroepiandrosterone-3- $\beta$-sulfate (II, DHEA-S), epiandrosterone-3- $\beta$-sulfate (III), androsterone-3- $\alpha$-sulfate (IV), and etiocholanol-17-one-3- $\alpha$-sulfate (V); and (B) total ion chromatogram (TIC) of a representative human urine sample. 

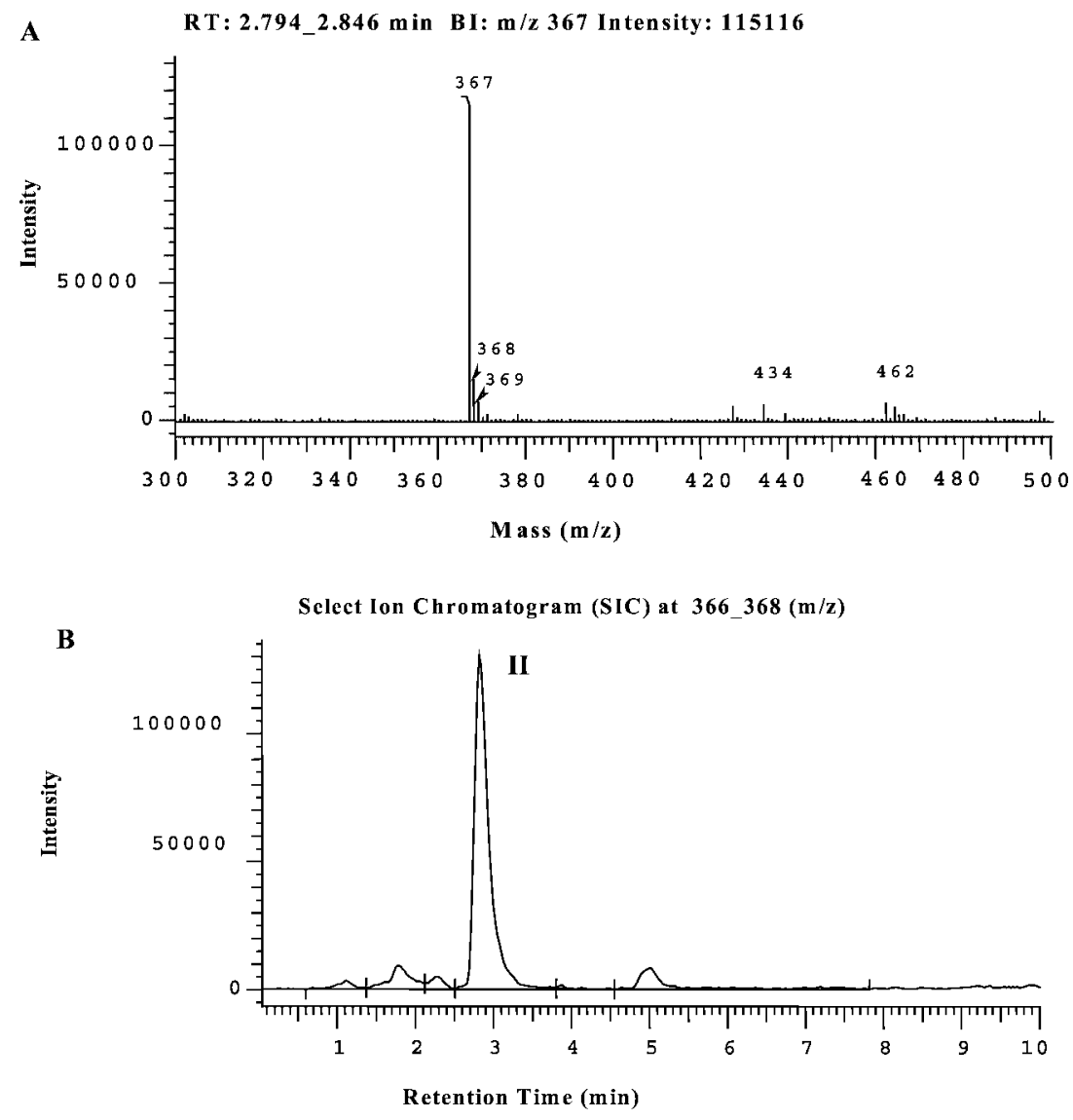

Fig. 3. (A) Mass spectrum and (B) select ion chromatogram (SIC) of DHEA-S (II) in a representative urine sample.

ion at $m / z=369$ (Fig. 4(A) \& (B)). However, Epiandrosterone-3- $\beta$-sulfate (III) eluted from the column quicker than androsterone-3- $\alpha$-sulfate (IV) and etiocholanol-17-one-3- $\alpha$-sulfate (V). There is a low intensity peak with same retention time as of DHEA-S that derived from its isotopic $[M+1]^{-}$ion. Since it has baseline separation from epiandrosterone-3- $\beta$-sulfate (III), it will not impact the quantification of epiandrosterone-3- $\beta$-sulfate (III), but rather help to confirm the identification of DHEA-S.

\subsection{Linearity and quantification limit}

The standard solution at various concentrations $(35,17.5,10.5,7,1.5,0.7,0.35$ and $0.15 \mathrm{ng} / \mu \mathrm{lof}$ total 17-KS-S) was analyzed as described with $1.5 \mathrm{ng} / \mu \mathrm{l}$ of total $17-\mathrm{KS}-\mathrm{S}$ solution as external standard. Linearity was expressed as a regression line forced through zero as shown in Table 1. Correlation coefficients for the seven 17-ketosteroids were between 0.9846 to 0.9987 . The limit of quantification (LOQ) for each 17-ketosteroid was determined by calculating the coefficient of variation (CV) of the peak areas with less than $20 \%$ out of five injections. The limit of quantification (LOQ) for 17-ketosteroids were from 0.5 to $2 \mathrm{pg} / \mu \mathrm{l}$. The upper limit of linearity was determined by $>0.98$ correlation coefficients based on a broader range of measurements. Over the upper calibration limit, the linearity was gradually disappeared, because of overflow of the ion trap in MS. The linearity range demonstrated from this analysis covered the normal concentration of total 17-ketosteroid sulfates $(3.04 \pm 2.54 \mathrm{ng} / \mu \mathrm{l})$ in urine [19]. 
RT: 3.389_3.440 min BI: m/z 369 Intensity: 32572

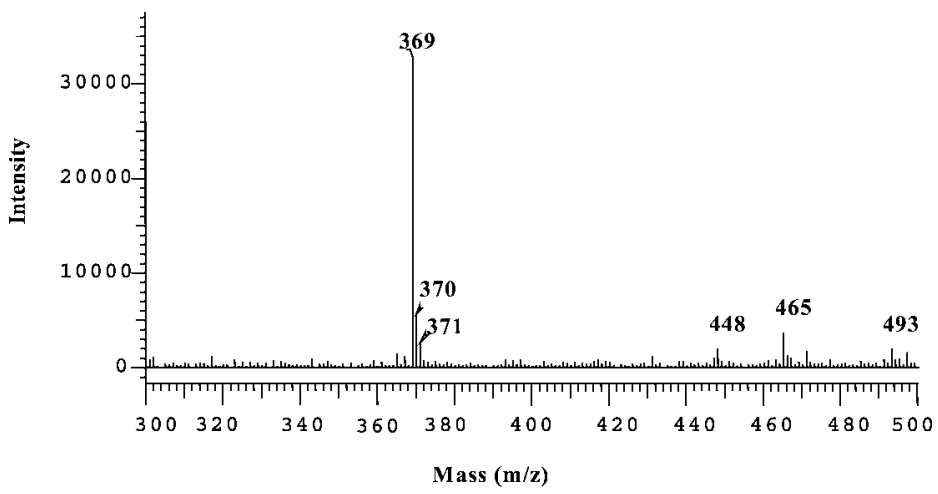

B

RT: $4.2224 .325 \mathrm{~min}$ BI: $\mathrm{m} / \mathrm{z} 369$ Intensity: 100669
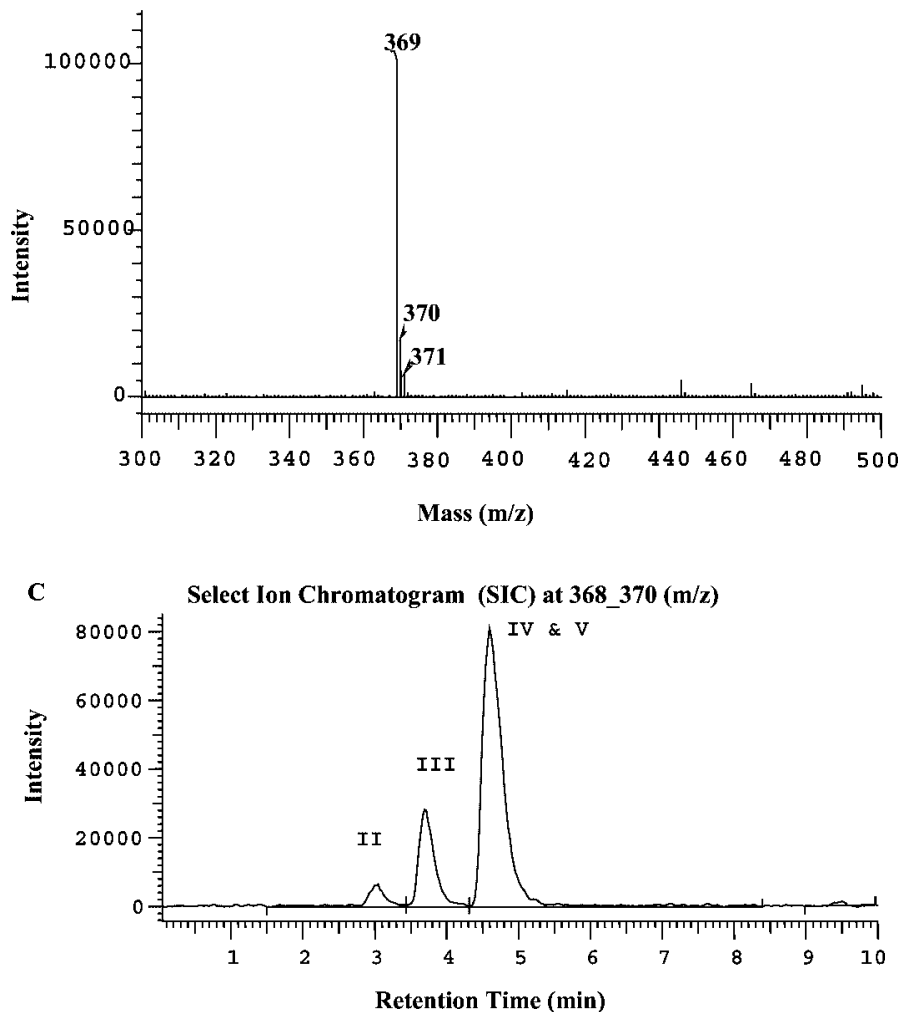

Fig. 4. (A) \& (B) Mass spectra and select ion chromatogram (SIC) of epiandrosterone-3- $\beta$-sulfate (III), androsterone-3- $\alpha$-sulfate (IV) and etiocholanol-17-one-3- $\alpha$-sulfate (V) in a representative urine sample.

\subsection{Standard recovery and stability}

At the concentrations of 1.5 and $6.0 \mathrm{ng} / \mu \mathrm{l}$ of total spiked standards, recovery for 17-ketosteroid sulfates were in the range of 64.8 to $98.5 \%$ (Table 2). The recovery yields of DHEA-S (70.9-72.4\%) at two different concentrations were consistent with published reports. Furthermore, total 17-ketosteroid sulfates composed of the four major sulfates, DHEA-S (II), epiandrosterone-3- $\beta$-sulfate (III), androsterone- 
Table 1

Linearity of 17-KS-S standards

\begin{tabular}{lcccc}
\hline 17-Ketosteroid sulfate & $\begin{array}{c}\text { Retention time } \\
(\mathrm{min})\end{array}$ & $\begin{array}{c}\text { Correlation } \\
\text { coefficient }\end{array}$ & $\begin{array}{c}\text { Linearity range } \\
(\mathrm{ng} / \mu \mathrm{l})\end{array}$ & $\begin{array}{c}\text { LOQ } \\
(\mathrm{pg} / \mu \mathrm{l})\end{array}$ \\
\hline DHEA-S (II) & 3.05 & 0.9846 & $0.03-14.04$ & 1 \\
Epiandrosterone-3- $\beta$-sulfate (III) & 3.69 & 0.9921 & $0.01-5.38$ & 0.5 \\
Androsterone-3- $\alpha$-sulfate (IV) & 4.60 & 0.9924 & $0.05-25.25$ & 2 \\
Etiocholanolone-3- $\alpha$-sulfate (V) & 4.60 & 0.9987 & $0.05-25.25$ & 2 \\
\hline
\end{tabular}

Table 2

17-KS standard recovery

\begin{tabular}{lccccccc}
\hline 17-Ketosteroid & $\begin{array}{c}\text { Baseline } \\
\text { concentration } \\
(\mathrm{ng} / \mu \mathrm{l})\end{array}$ & $\begin{array}{c}\text { Concentration } \\
(\mathrm{ng} / \mu \mathrm{l})\end{array}$ & $\begin{array}{c}\text { Recovery } \\
\end{array}$ & & $\begin{array}{c}\text { Concentration } \\
(\mathrm{ng} / \mu \mathrm{l})\end{array}$ & $\begin{array}{c}\text { Recovery } \\
(\%)\end{array}$ \\
\hline DHEA-S (II) & 1.510 & 0.169 & 70.9 & & 0.562 & 72.4 \\
Epiandrosterone-3- $\beta$-sulfate (III) & 0.376 & 0.065 & 86.7 & & 0.215 & 90.2 \\
Androsterone-3- $\alpha$-sulfate (IV) & 1.309 & 0.314 & 87.6 & & 1.044 & 85.3 \\
Etiocholanolone-3- $\alpha$-sulfate (V) & 0.594 & 0.293 & 98.5 & & 0.976 & 94.8 \\
\hline
\end{tabular}

3- $\alpha$-sulfate (IV), and etiocholanol-17-one-3- $\alpha$-sulfate (V), showed consistent recovery from the test concentrations, of $85.9 \%$ and $85.7 \%$, respectively. 17-ketosteroid sulfates were stable for 2 months at $-10 \pm 0.5^{\circ} \mathrm{C}$ with recovery of $96.1-107.2 \%$, without significant deviation $(\mathrm{CV} \leqslant 4.9 \%)$.

\subsection{Urine specimen analysis}

Total of 66 normal human volunteers participated in the 24-hour urine collection, which included 49 females and 17 males, aged 40 to 65 with average age of 50.3. Three urine samples were disqualified due to incomplete collection. Urine specimens collected in a period of $24 \mathrm{~h}$ were thawed at room temperature and processed as described on the same day of receipt. Individual 17-ketosteroid sulfate was quantified using the published method [19] and summarized in Table 3. The secretion amount of individual 17-KS-S in 24-h urine showed negative correlation with age based on Pearson coefficient with statistical significance $(p<0.05)$. This result is consistent with previous studies that demonstrated high serum and urinary DHEA-S (II) levels in young adults and decreasing with age [2,3].

Urinary total 17-ketosteroid sulfates that include compound II, III, IV and V had been used to represent an index of overall adrenal androgen production, at least before the onset of puberty [13]. It also had been reported declining with the beginning of disease until reaching very low levels during severe disease or old age [9]. Based on our observation, both 24-h secretion amount and concentration of 17-KS-S in 24-h urine specimen showed very significant $(p<0.002)$ negative correlation against age (Table 4$)$. Total 17KS-S concentration normalized with creatinine concentration, elicited as ACI, has also been confirmed statistically significant $(p=0.0041)$ decreasing with aging as published $[9,10]$.

Considering the inconvenience of urine collection in a period of 24-hours and needs to establish a baseline for 17-KS-S in single urine specimen for monitoring steroid abuse in sports and in dietary supplement consumption, a more extensive urine collections were initiated with total of 1565 participants. Sixty-three urine samples were disqualified due to unknown gender of participants, lack of age information, broken sample containers in the shipments, and individuals who consumed DHEA supplements. Out of the total 1502 qualified samples, 632 samples were sent from female participants, and 870 urines 
Table 3

Means \pm two times standard errors for 24-h urinary secretion ( $\mu \mathrm{g} / 24-\mathrm{h}) 17-\mathrm{KS}$ conjugates by age

\begin{tabular}{lcccccc}
\hline Age & $n$ & $\begin{array}{c}\text { Average } \\
\text { age }\end{array}$ & $\begin{array}{c}\text { DHEA-S } \\
(\text { II })\end{array}$ & $\begin{array}{c}\text { Epiandrosterone-S } \\
(\text { III })\end{array}$ & $\begin{array}{c}\text { Androsterone-S } \\
(\text { IV })\end{array}$ & $\begin{array}{c}\text { Etiocholanolone-S } \\
(\text { V) }\end{array}$ \\
\hline $40-45$ & 19 & 42.68 & $478.1 \pm 242.3$ & $169.2 \pm 86.0$ & $772.1 \pm 320.3$ & $351.6 \pm 181.7$ \\
$46-50$ & 20 & 48.75 & $518.3 \pm 402.1$ & $92.3 \pm 47.6$ & $526.1 \pm 252.2$ & $200.0 \pm 91.3$ \\
$51-55$ & 10 & 52.90 & $96.0 \pm 58.3$ & $27.4 \pm 22.5$ & $266.4 \pm 122.1$ & $76.67 \pm 68.46$ \\
$56-65$ & 14 & 61.14 & $84.5 \pm 80.7$ & $30.9 \pm 25.9$ & $121.3 \pm 92.8$ & $96.2 \pm 60.8$ \\
Pearson & -0.1058 & -0.2940 & -0.4073 & -0.4508 & -0.3619 \\
correlation & & & & & 0.0036 \\
coefficient & & & & & 0.0002 & \\
$P$ value & 0.4094 & 0.0193 & 0.0009 & & \\
\hline
\end{tabular}

Table 4

Means \pm two times standard errors for 24-h urinary total 17-KS-S, creatinine and ACI by age

\begin{tabular}{|c|c|c|c|c|c|c|}
\hline Age & $\begin{array}{c}\text { Average } \\
\text { age }\end{array}$ & $\begin{array}{c}\text { Total 17-KS-S } \\
\text { Secretion in } 24-\mathrm{h} \\
(\mu \mathrm{g} / 24 \mathrm{~h})\end{array}$ & $\begin{array}{c}\text { Total 17-KS-S } \\
\text { concentration } \\
(\mathrm{ng} / \mu \mathrm{l})\end{array}$ & $\begin{array}{c}\text { Creatinine } \\
\text { concentration } \\
(\mu \mathrm{g} / \mu \mathrm{l})\end{array}$ & $\begin{array}{c}\text { Creatinine } \\
\text { secretion in } 24-\mathrm{h} \\
(\mathrm{mg} / 24 \mathrm{~h})\end{array}$ & ACI \\
\hline 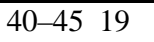 & 42.68 & $1771.12 \pm 786.85$ & $1.40 \pm 0.66$ & $0.93 \pm 0.21$ & $1134.08 \pm 256.68$ & $1.50 \pm 0.68$ \\
\hline $46-50 \quad 20$ & 48.75 & $1336.40 \pm 750.74$ & $1.27 \pm 0.60$ & $0.99 \pm 0.23$ & $1513.44 \pm 1277.88$ & $1.45 \pm 0.53$ \\
\hline $51-5510$ & 52.90 & $466.29 \pm 228.08$ & $0.38 \pm 0.21$ & $0.64 \pm 0.015$ & $890.94 \pm 201.8$ & $0.56 \pm 0.32$ \\
\hline $56-65 \quad 14$ & 61.14 & $187.90 \pm 93.95$ & $0.27 \pm 0.10$ & $0.61 \pm 0.14$ & $601.40 \pm 187.1$ & $0.53 \pm 0.26$ \\
\hline $\begin{array}{l}\text { Pearson } \\
\text { correlation } \\
\text { coefficient }\end{array}$ & & -0.4026 & -0.3976 & -0.2600 & -0.1312 & -0.3571 \\
\hline$P$ value & & 0.0011 & 0.0013 & 0.0396 & 0.3053 & 0.0041 \\
\hline
\end{tabular}

were collected by males. The urine specimens were collected in early morning between 8 to 10 am following the general guideline. The samples were preserved with boric acid and thymol and tested in 48 hours after the collection. Since there is no volume measurement required for those specimens, the test results were expressed as a normalized total 17 -ketosteroid sulfates against creatinine $(\mathrm{ng} / \mu \mathrm{g})$. Figure 5 illustrated the distribution of normalized total 17-KS-S concentration in relation to age from 1514 urine specimens and fitted linear regression lines. The calculated linear functions of normalized total 17-KS-S (ACI) against age are: $\mathrm{ACI}=2.62-0.026 \times$ age. The negative coefficient in this equation indicates a general decreasing of 17-ketosteroid sulfates with age that is statistically very significant with $p$-value being equal to 0.0001 . This result is consistent with the finding reported in this manuscript from the 24 -four urine samples. It demonstrated the validity of $17-\mathrm{KS}-\mathrm{S}$ value using the urine sample collected once in morning versus 24-hour collection.

Gender has been reported as a factor that affects secretion of DHEA, DHEA-S, and total 17-KS-S [4]. Our analysis also confirmed that male has significantly higher 24-h secretion amount of DHEA-S and total 17-KS-S in 24-hour urine than the same age of female, $p$-values equal to 0.0046 and 0.0012 , respectively, after analysis of covariance. However, gender was not significant after analysis of covariance with normalized 17-KS-S (ACI) as an outcome variable for 24-hour urine samples.

ANCOVA analysis was performed to look at gender and age effects simultaneously on urine samples collected in morning. The interaction term was not statistically significant with $p$-value equal to 0.3547 . 


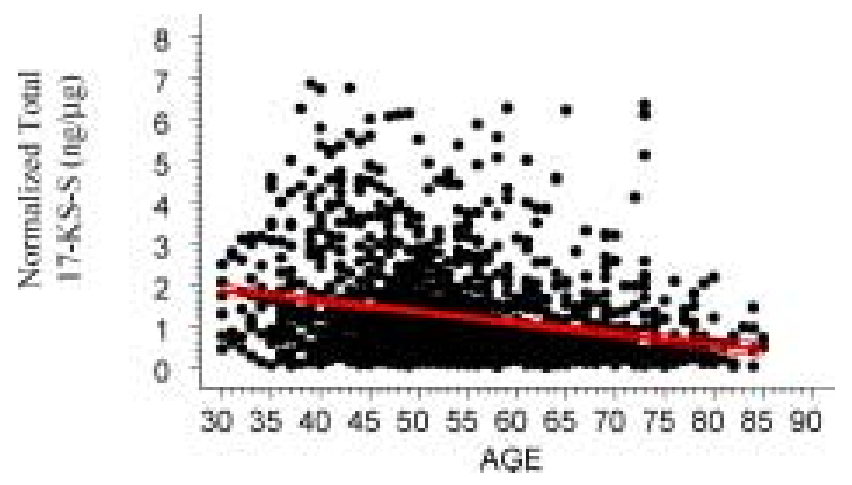

Fig. 5. Normalized total 17-KS-S concentration in relation to age from 1514 urine specimens.

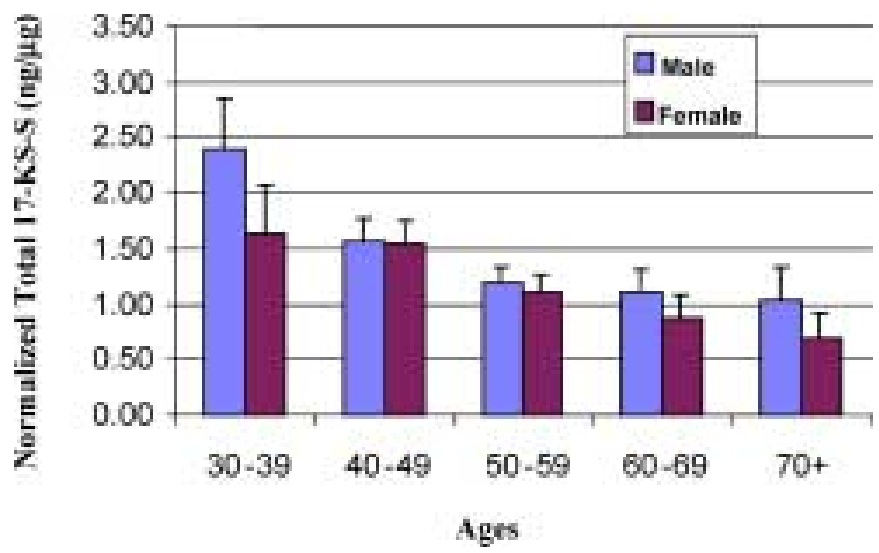

Fig. 6. The means of normalized 17-KS-S by gender and age groups.

However, gender is a statistically significant factor with $p$-value being equal to 0.0067 after removing the interaction term from the model. Specifically, males tend to have higher values of ACI for a given age than females and the absolute amount of difference between gender is the relatively same over the age range under investigation as shown in Fig. 6.

\section{Conclusion}

Current methods used to determine biological age include measurements of skin thickness, strength, stamina, body composition, reaction time, hearing, visual acuity, and whole blood lymphocyte analysis. Unfortunately, most of these tests do not directly measure aging as an active, kinetic process but rather as clinical endpoints. However, a ratio of urinary total 17-ketosteroid sulfate concentrations $(\mathrm{ng} / \mu \mathrm{l})$ to creatinine concentration $(\mu \mathrm{g} / \mu \mathrm{l})$ expressed as the ACI (Anabolic/Catabolic Index) has been reported to be sensitive enough to reflect the full range of repair/rebuild activity in muscles, organs, connective tissue, immune and nervous system $[4,9,10]$. A high-performance liquid chromatography and ion trap mass spectroscopic method for the quantification of individual urinary 17-ketosteroid sulfates was developed as a simple, accurate and high-throughput research and diagnostic technique. Normal ranges of normalized 17-ketosteroid sulfates in 24-h urinary secretion and in urines collected in morning have been 
established. The statistically significant negative correlations between age and normalized total 17-KS-S conjugates in both types of urines were observed. This LC/MS method will supply a sensitive, convenient and accurate tool to quantify individual and total 17-KS sulfates in human urine, which could be used in establishment of relation between the steroids and aging/disease, and in the recommendation of proper dosages for DHEA/DHEA-S replacement therapy.

\section{Acknowledgements}

The authors wish to thank Dr. Steve Orndorff, Mr. Michael Chtourou, Mrs. Andria Robbins, Mrs. Barbara Westrick, Mr. Sean Johnson and Mrs. Judy Li from Univera Pharmaceuticals, Inc.; and Dr. Ruidan Chen, and Dr. Peter Grosshans from Hitachi Instruments, Inc. for technical assistance. We wish to thank California Skin Research Institute at San Diego to conduct 24-hour urine specimen collection; and Mr. Stephen Cherniske and Oasis Wellness Network at Broomfield, Colorado to conduct morning urine specimen collection and to support this study.

\section{References}

[1] W. Regelson, R. Loria and M. Kalimi, Ann. NY Acad. Sci. 719 (1994), 553.

[2] J. Šulcová, M. Hill, R. Hampl and L. Stárka, J. Endocrinol. 154 (1997), 57.

[3] E.G. Birkenhager-Gillesse, J. Derksen and A.M. Lagaay, Ann. NY Acad. Sci. 719 (1994), 543.

[4] P.D. Kroboth, F.S. Salek, A.L. Pittenger, T.J. Fabian and R.F. Freye, J. Clin. Pharmcol. 39 (1999), 327.

[5] J.P. Hinson and P.W. Raven, J. Endocrinol. 163 (1999), 1.

[6] R.A. Lobo, W.L. Paul and U. Goebelsmann, Obstet. Gynecol. 57 (1981), 69.

[7] L. Dehennin, M. Ferry, P. Lafarge, G. Peres and J.P. Lafarge, Steroids 63 (1998), 80.

[8] A.E. Field, G.A. Colditz, W.C. Willett, C. Longcope and J.B. McKinlay, J. Clin. Endocrinol. Metab. 79 (1994), 1310.

[9] O. Nishikaze and E. Furuya, J. UOEH 20 (1998), 273.

[10] E. Furuya, M. Maezawa and O. Nishikaze, Jpn. J. Clin. Pathol. 46 (1998), 529.

[11] D.A. Granger, E.B. Schwartz, A. Booth, M. Curran and D. Zakaria, Psychoneuroendocrinol. 24 (1999), 567.

[12] T. Feher, Acta Med. Acad. Sci. Hung. 28 (1971), 227.

[13] T. Remer, A. Hintelmann and F. Manz, Steroids 59 (1994), 16.

[14] T. Kawasaki, M. Maeda and A. Tsuji, J. Chromatogr. 233 (1982), 61.

[15] M.H. Choi, K.R. Kim and B.C. Chung, Steroids 65 (2000), 54.

[16] M.A. Zemaitis and P.D. Kroboth, J. Chromatogr. B. 716 (1998), 19.

[17] C.H.L. Shackleton, C. Kletke, S. Wudy and J.H. Pratt, Steroids 55 (1990), 472.

[18] H. Zhang and J. Henion, Anal. Chem. 71 (1999), 3955.

[19] Q. Jia, M.F. Hong, Z.X. Pan and S. Orndorff. J. Chromatogr. B. 750 (2000), 81.

[20] D. Heinegard and G. Tiderstrom, Clin. Chim. Acta 43 (1973), 305.

[21] B. Rosner, Fundamentals of Biostatistics PWS-KENT Publishing Company, 1990, p. 441.

[22] M.P. Kushnir, National Underwriter Life \& Health 100 (1996), 16.

[23] F.A. Huppert, W. Solomou, S. O'Connor, K. Morgan, P. Sussams and C. Brayne, Exp. Gerontol. 33 (1998), 593. 


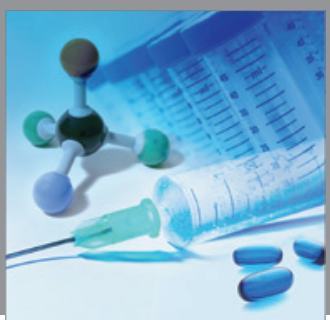

International Journal of

Medicinal Chemistry

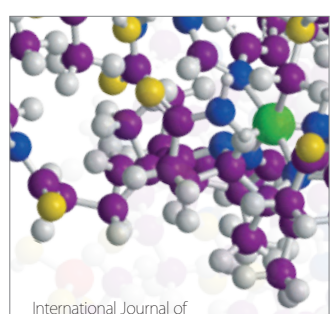

Carbohydrate Chemistry

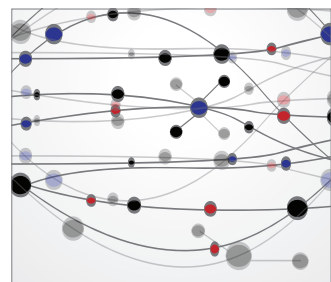

The Scientific World Journal
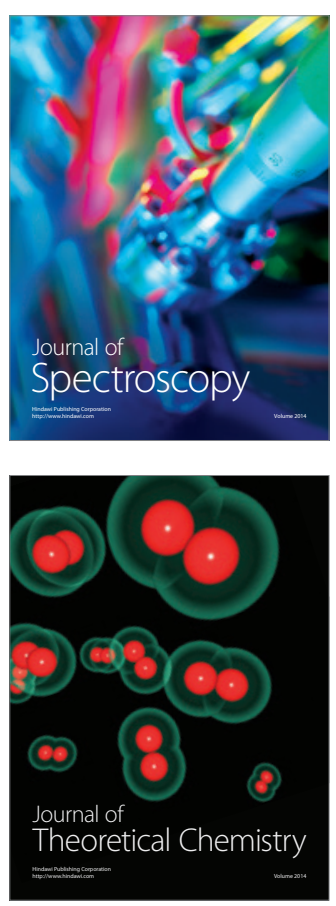
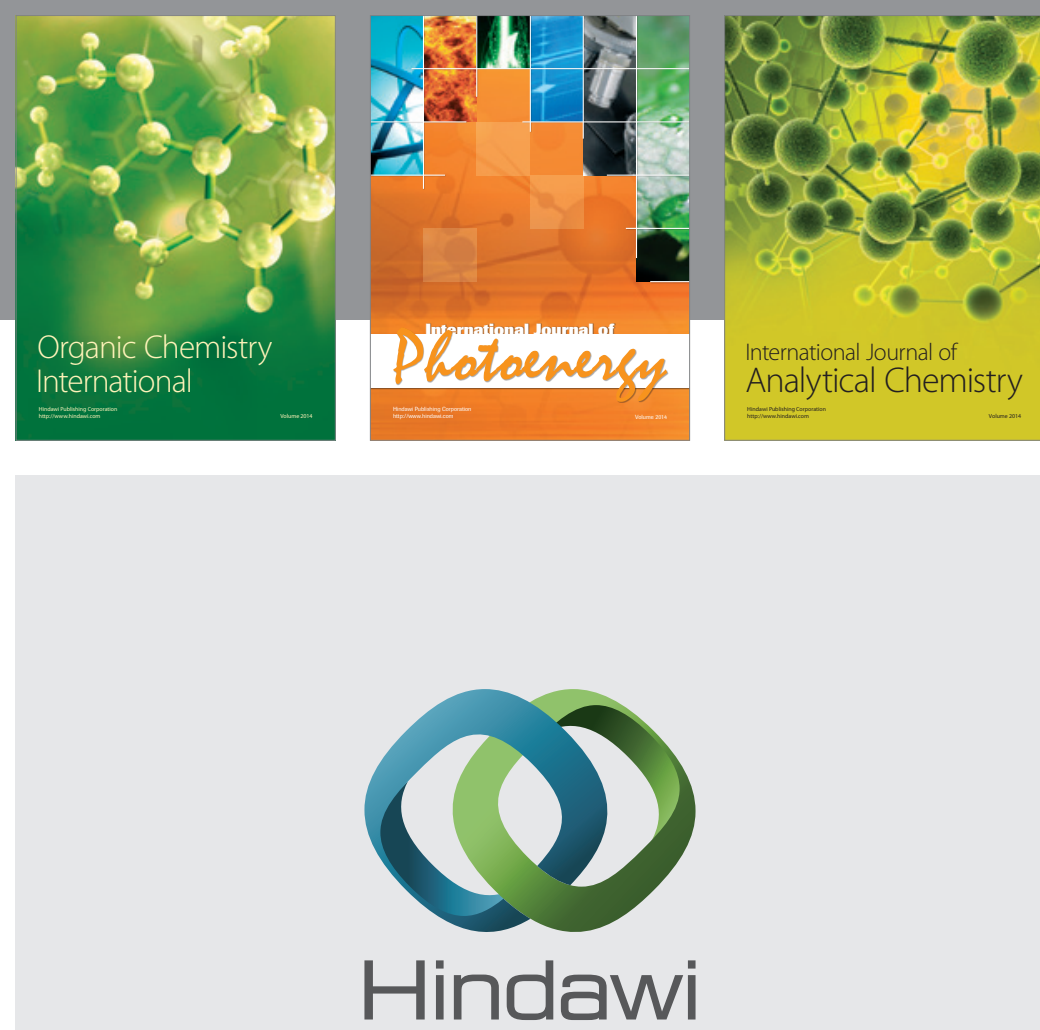

Submit your manuscripts at

http://www.hindawi.com
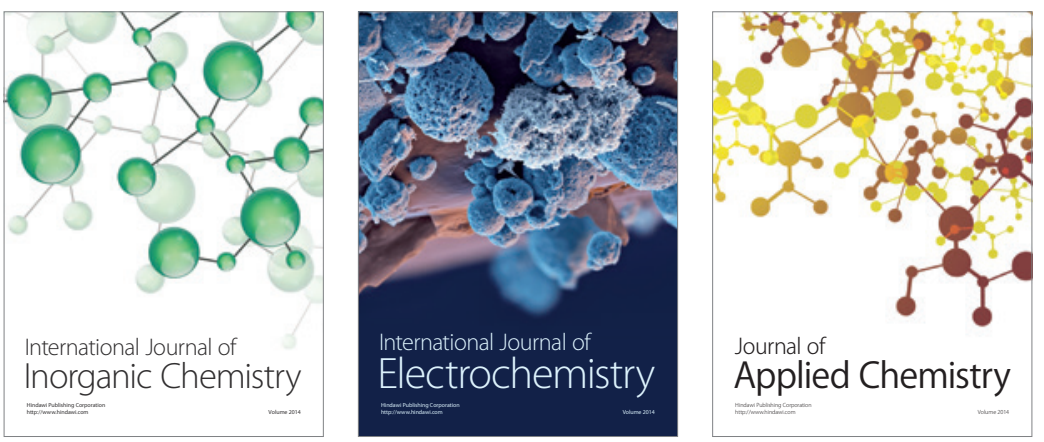

Journal of

Applied Chemistry
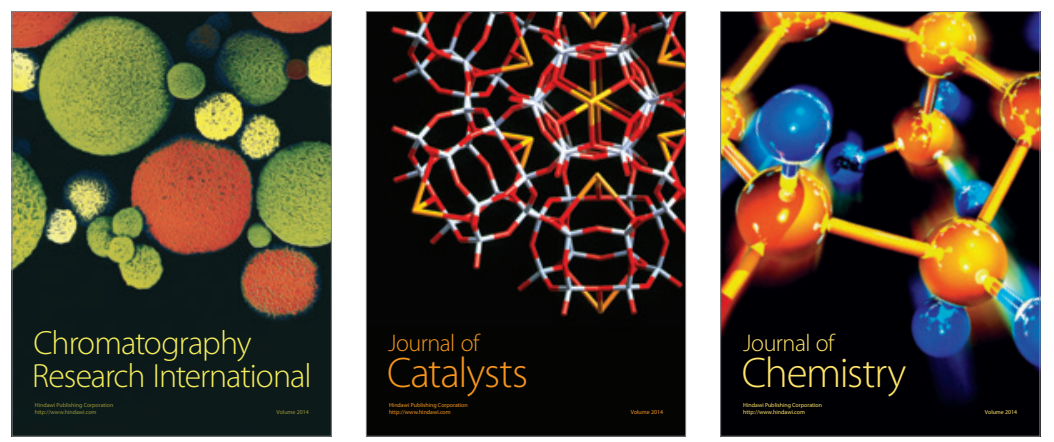
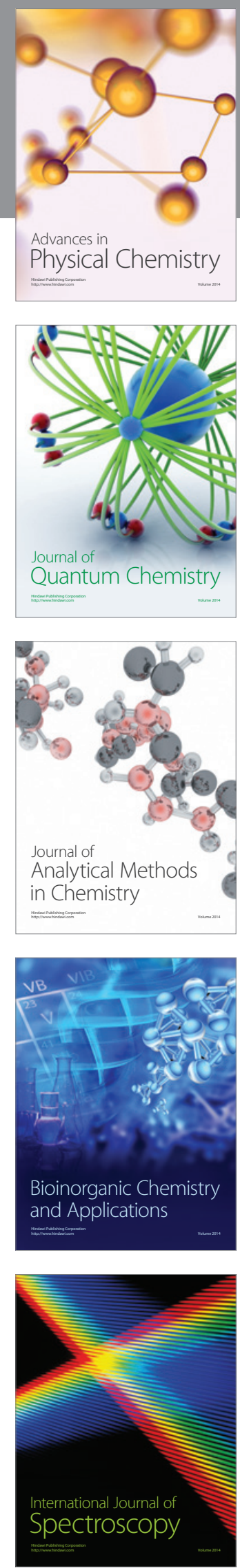